\title{
Neutrophil-to-lymphocyte Ratio and Platelet-to-lymphocyte Ratio as Predictors of the Early Requirement of Mechanical Ventilation in COVID-19 Patients
}

\author{
Parvathy R Nair ${ }^{1}$, Souvik Maitra ${ }^{2}$, Bikash R Ray ${ }^{3}$, Rahul K Anand ${ }^{4}$, Dalim K Baidya ${ }^{5}$, Rajeshwari Subramaniam ${ }^{6}$
}

Keywords: Coronavirus, Mechanical ventilation, Neutrophil-to-lymphocyte ratio, platelet-to-lymphocyte ratio.

Indian Journal of Critical Care Medicine (2020): 10.5005/jp-journals-10071-23663

Dear Sir,

Since the first case diagnosed in Wuhan, China, more than 7 million people have been infected with novel coronavirus (SARSCoV-2) infection. 'Though the mortality rate varies across countries, an early estimate of the case fatality rate was around $2-3 \% .^{2,3}$ Despite the low case fatality rate, the total number of cases in different countries has increased and overwhelmed the healthcare infrastructures. Identification of high-risk population requiring early invasive mechanical ventilation support is paramount to arrange and allocate costly resources like ventilators. Elevated markers of inflammation and a reduction in lymphocyte count have been associated with severe SARS-CoV-2 infection. ${ }^{4}$ In previous researches, neutrophil-tolymphocyte ratio (NLR) was found to be a predictor of severe adult respiratory distress syndrome (ARDS) and mortality. ${ }^{5,6}$ However, it is important to find an easily available and cost-effective investigation, which can predict the early requirement of mechanical ventilation in the emergency department.

In this interim analysis of an ongoing prospective study, we evaluated whether NLR and platelet-to-lymphocyte ratio (PLR) can predict the early requirement of mechanical ventilation in moderate to severe COVID-19 patients admitted in a tertiary care teaching hospital.

Ninety-three patients were analyzed, and among them, 24 patients required invasive mechanical ventilation within 24 hours of admission. Non-parametric tests were used for analysis and the area under the receiver operating characteristics curve (AUROC) with a $95 \%$ confidence interval $(\mathrm{Cl})$ was computed.

Median (interquartile range, IQR) age was 50 (37-59) years and $61.3 \%$ of all patients were male. There was no difference in the distribution of the age of patients who required mechanical ventilation within 24 hours of admission ( $p=0.57$, Mann-Whitney $\mathrm{U}$ test). Patients who required mechanical ventilation had higher baseline total leukocyte count ( $p=0.001$, Mann-Whitney U test), higher absolute neutrophil count ( $p=0.002$, Mann-Whitney
${ }^{1-6}$ Department of Anesthesiology, Pain Medicine and Critical Care, All India Institute of Medical Sciences, New Delhi, India

Corresponding Author:Dalim KBaidya, Department of Anesthesiology, Pain Medicine and Critical Care, All India Institute of Medical Sciences, New Delhi, India, Phone: +9111-26593743, e-mail: dalimkumar.ab8@ gmail.com

How to cite this article: Nair PR, Maitra S, Ray BR, Anand RK, Baidya DK, Subramaniam R. Neutrophil-to-lymphocyte Ratio and Plateletto-lymphocyte Ratio as Predictors of the Early Requirement of Mechanical Ventilation in COVID-19 Patients. Indian J Crit Care Med 2020;24(11):1143-1144.

Source of support: Nil

Conflict of interest: None

U test) but similar absolute lymphocyte count $(p=0.65)$ and platelet count ( $p=0.13$ ). Neutrophil-to-lymphocyte ratio was significantly higher in patients who required mechanical ventilation [median (IQR) 5.8 (4.6-9) vs $3.9(2.2-5.3) ; p=0.003$ ] but PLR was similar $(p=0.41)$. All these data have been depicted in Table 1. Neutrophil-to-lymphocyte ratio was not an excellent predictor of the requirement of mechanical ventilation in the first 24 hours of hospital admission [AUROC $(95 \% \mathrm{CI}) 0.71(0.58-0.84)$, Fig. 1]. The best cut-off value obtained from Youden's index was 4.6 with a sensitivity of $79.2 \%$ and specificity of $62.3 \%$. The PLR had an AUROC $(95 \% \mathrm{Cl})$ of $0.56(0.42-0.69)$ to predict the requirement of mechanical ventilation.

In a previous series of 81 patients, Ma et al. identified that NLR and PLR had similar AUROC ( 0.71 and 0.59 , respectively) to predict the development of ARDS in COVID-19 patients. ${ }^{6}$ Although NLR $>11$ predicted the development of moderate to severe ARDS and NLR $>9.8$ could predict the overall requirement of ventilation in that study, the development of early deterioration was not analyzed. ${ }^{6}$ In another prospective cohort of COVID-19 patients

Table 1: Data of patients with and without mechanical ventilation within 24 hours. Data expressed as median (interquartile range), Mann-Whitney $U$ test was applied for all analysis

\begin{tabular}{llll}
\hline Parameters & Mechanical ventilation $(n=24)$ & No mechanical ventilation $(n=69)$ & Significance \\
\hline Age & $52.5(40.5-59)$ & $50(35-59)$ & $p=0.571$ \\
Total leukocyte count & $12,200(9,200-15,050)$ & $7,500(5,300-11,400)$ & $p=0.001$ \\
Absolute neutrophil count & $9,397(6,610-12,082)$ & $5,103(3,699-9,112)$ & $p=0.002$ \\
Absolute lymphocyte count & $1,420(1,237-2,180)$ & $1,380(980-1,866)$ & $p=0.651$ \\
Platelet count $\left(\times 10^{5}\right)$ & $1.31(0.76-2.13)$ & $1.72(1.14-2.42)$ & $p=0.132$ \\
\hline
\end{tabular}

(c) The Author(s). 2020 Open Access This article is distributed under the terms of the Creative Commons Attribution 4.0 International License (https://creativecommons. org/licenses/by-nc/4.0/), which permits unrestricted use, distribution, and non-commercial reproduction in any medium, provided you give appropriate credit to the original author(s) and the source, provide a link to the Creative Commons license, and indicate if changes were made. The Creative Commons Public Domain Dedication waiver (http://creativecommons.org/publicdomain/zero/1.0/) applies to the data made available in this article, unless otherwise stated. 


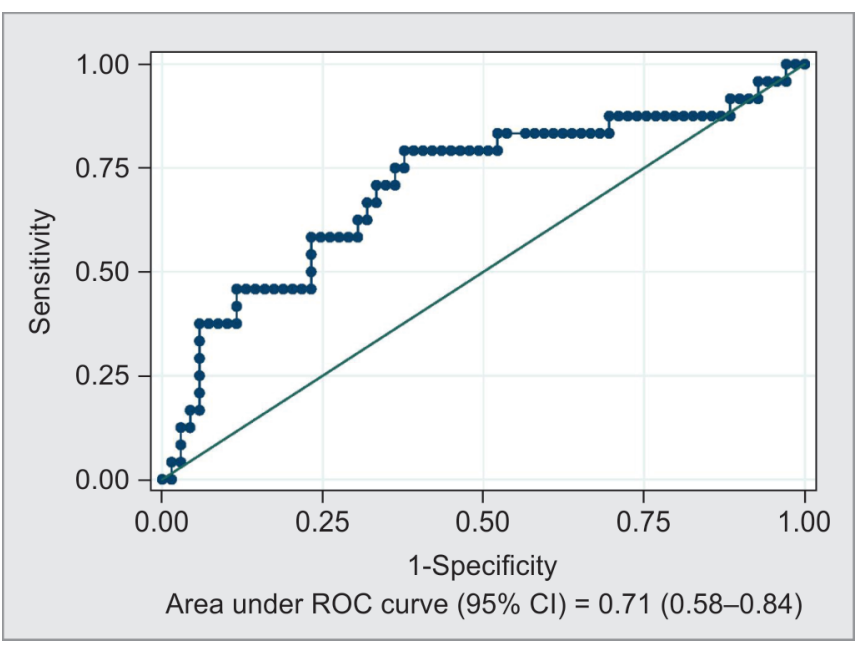

Fig. 1: ROC curve of NLR as predictor of early mechanical ventilation

from Wuhan, China, a relatively lower NLR value of $>3.13$ predicted the development of critical illness in patients aged $>50$ years. ${ }^{7}$ However, none of the previous studies attempted to identify the early requirement of ventilation within 24 hours. We found that sensitivity and specificity of NLR $>4.6$ were moderately good in predicting the requirement of ventilation within 24 hours.

It is important to find a common and easily available blood parameter like NLR at admission to predict the early requirement of ventilation in COVID-19 because (a) severity of hypoxia may not be a good predictor of mechanical ventilation due to mismatch between oxygenation and lung mechanics ${ }^{8}$ and (b) at a later stage, various other clinical, laboratory, and radiological parameters being available may help prediction of the further course of the disease. Therefore, the moderate performance of NLR and PLR in this regard warrants further studies from a larger data set to search for a better predictor.

\section{Availability of Data and Material}

The datasets used and/or analyzed during the current study are available from the corresponding author on reasonable request.

\section{Ethics Approval and Consent to Participate}

The study was approved by the Ethics committee of All India Institute of Medical Sciences New Delhi, vide letter number IEC-321/27.04.20 dated May 11, 2020, and consent was obtained from all the patients or their legally acceptable representatives.

\section{Author Contribution}

Souvik Maitra, Bikash R Ray, and Dalim K Baidya had participated in the concept and design of the study. Parvathy R Nair, Souvik Maitra, and Rahul K Anand contributed to data acquisition. Souvik Maitra did the statistical analysis. Dalim K Baidya and Bikash R Ray did the manuscript writing and Rajeshwari Subramaniam did the manuscript editing. All the authors reviewed and approved the final manuscript.

\section{References}

1. Huang C, Wang Y, Li X, Ren L, Zhao J, Hu Y, et al. Clinical features of patients infected with 2019 novel coronavirus in Wuhan, China. Lancet 2020;395(10223):497-506. DOI: 10.1016/S0140-6736(20) 30183-5.

2. Wu Z, McGoogan JM. Characteristics of and important lessons from the coronavirus disease 2019 (COVID-19) outbreak in China: summary of a report of 72314 cases from the Chinese center for disease control and prevention. JAMA 2020;323(13):1239-1242. DOI: 10.1001/ jama.2020.2648.

3. Maitra S, Biswas M, Bhattacharjee S. Case- fatality rate in COVID- 19 patients: a meta-analysis of publicly accessible database. medRxiv 2020. DOI: 10.1101/2020.04.09.20059683.

4. Sun Y, Dong Y, Wang L, Xie H, Li B, Chang C, et al. Characteristics and prognostic factors of disease severity in patients with COVID-19: the Beijing experience. J Autoimmun 2020;112:102473. DOI: 10.1016/j. jaut.2020.102473.

5. Liu Y, Du X, Chen J, Jin Y, Peng L, Wang HHX, et al. Neutrophil-tolymphocyte ratio as an independent risk factor for mortality in hospitalized patients with COVID-19. J Infect 2020;81(1):e6-e12. DOI: 10.1016/j.jinf.2020.04.002.

6. Ma A, Cheng J, Yang J, Dong M, Liao X, Kang Y. Neutrophil-tolymphocyte ratio as a predictive biomarker for moderate-severe ARDS in severe COVID-19 patients. Crit Care 2020;20(1):288. DOI: 10.1186/s13054-020-03007-0.

7. Liu J, Liu Y, Xiang P, Pu L, Xiong H, Li C, et al. Neutrophil-to-lymphocyte ratio predicts critical illness patients with 2019 coronavirus disease in the early stage. J Tranl Med 2020;18(1):206. DOI: 10.1186/s12967020-02374-0.

8. Gattinoni L, Coppola S, Cressoni M, Busana M, Rossi S, Chiumello D, et al. COVID-19 does not lead to a "typical" acute respiratory distress syndrome. Am J Respir Crit Care Med 2020;201(10):1299-1300. DOI: 10.1164/rccm.202003-0817LE. 